\title{
Los retos pendientes para una reforma del gobierno local que implique a las Comunidades Autónomas
}

\author{
Andrés Boix Palop \\ Universitat de València-Estudi General' \\ Andres.Boix@uv.es
}

\section{DEL FRACASO DE LA REFORMA LOCAL DE 2013}

Concluida la legislatura comenzada a finales de 2011 -con períodos de sesiones de principios de 2012 a finales 2015-, así como la primera de sus prórrogas -la breve legislatura que ha cubierto el primer semestre de 2016- y en vísperas de que haya de dar comienzo, necesariamente, una nueva -sea con elecciones mediante o sin ellas- puede ser conveniente echar la vista atrás para valorar algunas de las reformas que han protagonizado este tiempo. Un tiempo marcado por un contexto muy peculiar, de crisis económica pero también social e institucional en España, así como de indisimulada presión por parte de las instituciones europeas, que quizás explique, al menos en parte, tanto los orígenes de las mencionadas reformas como algunas de sus insuficiencias.

La reforma local aprobada definitivamente por las Cortes a finales de 2013 -esto es, a mitad de la legislatura en cuestión- es un buen ejemplo de ello. Forma parte del «paquete de reformas» que el Gobierno de España impulsó con la idea de «racionalizar» la Administración española, junto a otras muchas iniciativas, tras las que se atisba no sólo la evidente necesidad de hacer frente a la grave situación económica sino la no menos patente presión por parte de las instituciones de la Unión Europea, muy preocupadas en esos años ante la posibilidad de que la situación económica e institucional de España pudiera repercutir negativamente en la estabilidad tanto del propio proyecto europeo como de la moneda que comparten muchos de sus miembros, entre ellos nuestro país. No es casualidad, por ejemplo, que el Memorando de Entendimiento acordado entre el Reino de España y la Facilidad de Estabilización Financiera Europea en nombre de la Unión Europea a fin de determinar las condiciones de política sectorial y financiera que se imponían a España a cambio de la financiación acordada dentro del Acuerdo Marco de Asistencia Financiera, que permitió al gobierno español acometer el saneamiento de las entidades de crédito con más dificultades, se firme precisamente el 24 de julio de 2012 -por mucho que tarde medio año en ser publicado en el Boletín Oficial del Estado-, tras meses de enormes presiones y turbulencias en los mercados financieros que amenazaban con comprometer no sólo todo el mercado del crédito español sino con afectar de forma muy grave a los de los socios europeos. El gobierno de España, a cambio de esta inyección económica -instrumentada en forma del conocido «crédito en condiciones muy ventajosas»- se comprometía a acometer una importante cantidad de reformas. Las unas, plasmadas en el documento y resultado de la explícita condicionalidad que vehicula el Memorando, que tenían que ver con el saneamiento del propio sector financiero español y su marco regulador. Las otras, sin necesidad de que aparecieran comprometidas en el documento escrito, firmado y publicado, pero que a nadie se le escapaba que eran fruto de presiones y recomendaciones europeas con una fuerza casi equivalente a las que sí aparecían plasmadas, tenían que ver con la necesidad inaplazable de que nuestro país pusiera en marcha importantes reformas en otros sectores de nuestras economía y, también, en nuestras Administraciones públicas con el objetivo indeclinable de lograr su «modernización», «racionalización», «eliminación de duplicidades», «adaptación a los modelos imperantes en los países de nuestro entorno más avanzados», «sostenibilidad»... Todo ello formas más o menos elegantes de expresar cuál era en realidad el mandato en cuestión, impuesto por la Unión Europea y asumido por el gobierno español, que de forma mucho más sencilla y directa se puede traducir como la necesidad imperiosa y urgente de hacer recortes y lograr importantes ahorros en el gasto público de nuestras corporaciones locales, aparatos burocráticos de las Comunidades Autónomas y estructura orgánica de la Administración del Estado.

1 Andrés Boix Palop es Profesor de Derecho Administrativo en la Universitat de València-Estudi General. Correo electrónico: Andres. Boix@uv.es. Twitter: @Andres_Boix.Blog sobre Derecho público y página web personal: http://www.uv.es/aboixp. 
Las presiones exógenas explican en buena parte tanto cierta precipitación a la hora de poner en marcha estos procesos de transformación como las manifiestas carencias en la correcta evaluación de los objetivos que se perseguían o los fines que se pretendían alcanzar. Asimismo, influyen en una de las características más significativas y originales de todo el proceso: el hecho de que las reformas en sí fueran en no pocas ocasiones menos importantes que transmitir la imagen, tanto ante la Unión Europea como ante «los mercados», con la evidente intención de tranquilizarlos, de que se estaba llevando a cabo un muy importante esfuerzo reformista, más allá de si luego éste se concretaba, a medio y largo plazo, en cambios de verdadero fuste.

No es de extrañar, por lo demás, a partir de este planteamiento, y dado el liderazgo del gobierno central en todo el proceso, que los cambios efectivamente operados hayan sido mucho más intensos sobre las Comunidades Autónomas y Entes Locales que sobre la propia estructura de la Administración de un Estado que es juez y parte en el proceso de evaluar dónde puedan estar las ineficiencias y órganos innecesarios. El informe emitido al efecto por la Comisión para la Reforma de las Administraciones Públicas (CORA), presentado en julio de 2013, es muy significativo, por cuanto apenas sí logra detectar organismos superfluos o procesos de racionalización que conlleven una reducción del perímetro de la Administración del Estado, más allá de cuestiones absolutamente anecdóticas -que llevan a reorganizar, que no a suprimir, elementos de una centralidad tal como la forma en que se gestionan la cría caballar o la administración de ciertos templos de culto, ambos casos sorprendentes ejemplos de responsabilidades estatales llamativas en el siglo xxı; o a proponer que las Administraciones autónomas se ocupen de la vacunación de los españoles que viajan al exterior, pero poco más-. En cambio, las duplicidades e ineficiencias detectadas que son atribuidas tanto a las Comunidades Autónomas como a los Entes Locales son mucho mayores. Razón por la cual el grueso de los míticos 8.000 millones de euros -cifra que por lo demás ha ido variando en la comunicación gubernamental a la hora de determinar si correspondía al objetivo de ahorro anual o a la suma de las economías de varios ejercicios- que ha de defenderse ante la Unión Europea que se han logrado «optimizar» se aspira a que salga, a la postre, de reformas impuestas tanto a unas como a otros. La forma en que se logrará imponer estos ahorros al resto de Administraciones Públicas, en lo que se refiere a las Comunidades Autónomas, ha sido por la vía de las medidas de ajuste en materia de sostenibilidad que, al amparo de las competencias estatales horizontales en materia de economía y déficit público, se ha considerado que permiten al Estado no sólo el establecimiento de draconianos objetivos de déficit público al resto de Administraciones -las cifras en que se ha concretado el ajuste al que se ha obligado a las Comunidades Autónomas, por mucho que sean éstas las responsables de prestar los servicios públicos más intensivos en capital humano y más necesitados de recursos, como son la sanidad o la educación públicas, han sido siempre mucho más exigentes que las que el Estado se ha impuesto a sí mismo, como ha sido denunciado hasta la saciedad- sino la imposición de planes de ajuste si éstos son incumplidos, así como el establecimiento de todo tipo de reglas respecto a la determinación del gasto público. Estas reglas se ha aceptado que puedan afectar incluso a la determinación que una Comunidad Autónomas haga de cómo destinar sus recursos en el ejercicio de sus competencias exclusivas, para las que el Estado puede prohibir o limitar, por medio de las conocidas «tasas de reposición», incluso la contratación del personal que las administraciones responsables de la prestación del servicio, sean autonómicas o locales, puedan considerar necesario. De hecho, el grueso de los «ahorros» en «racionalización» logrado por estas medidas durante los años pasados se explica de forma directa a partir, sencillamente, de estas imposiciones en materia de déficit público y limitación en el número de nuevas contrataciones de personal. Las economías efectivamente obtenidas se corresponden casi miméticamente con la reducción del número de empleados públicos.

Con todo, y junto a estas medidas, los dos primeros años de legislatura vehicularon una apasionada discusión sobre el modelo de gobierno local existente en España, tanto a nivel provincial como local. La reforma finalmente plasmada en la Ley 27/2013, de Racionalización y Sostenibilidad de la Administración Local (LRSAL), intervenida tras dos años de debate, trataba de acompañar y completar los recortes presupuestarios y las posibilidades de intervención en las cuentas públicas de los entes locales españoles con una supuesta reforma que aspiraba a modernizar definitivamente nuestra planta local y dar solución a algunos de los problemas endémicos del municipalismo español. Liderada por el Ministerio de Hacienda y Administraciones Públicas con la colaboración del Instituto Nacional de Administración Pública, las propuestas que finalmente quedaron plasmadas en la norma aspiraban a resolver, al menos, cinco problemas esenciales con la idea de modernizar definitivamente nuestras administraciones locales: la cuestión de la planta local y el excesivo número de municipios existentes en España -que se juzgan demasiados y por lo general demasiado pequeños para poder prestar de forma eficiente los servicios públicos-, el papel de las administraciones de segundo nivel -supramunicipal, provincial-, la ordenación de las competencias locales y la intervención en la misma de las Comunidades Autónomas, la cuestión de la financiación suficiente de los entes locales y, por último, la eficiente prestación de sus servicios públicos.

La reforma de 2013 ha sido, en efecto, incluso tras los diluidos planteamientos respecto de lo que fueron algunos de sus objetivos iniciales con que quedó plasmada legalmente (Santamaría Pastor, 2014), el mayor in- 
tento de reforma del régimen local español desde su implantación en los perfiles que actualmente conocemos con la Ley Reguladora de las Bases del Régimen Local de 1985 (LRBRL). Podemos, sin embargo, considerar que en todos y cada uno de los referidos ejes esenciales las orientaciones de la misma, casi tres años después de su aprobación, se han manifestado como fracasadas, bien por la incorrecta evaluación de la efectiva necesidad de una reforma en ese punto, bien por la incapacidad de la norma para impulsar cambios efectivos, bien por la patente equivocación en algunas de las finalidades perseguidas, que el tiempo ha puesto si cabe más de relieve. Así, la reforma apostó por la fusión de los ayuntamientos y la consiguiente reducción del número de municipios, pero no ha logrado ni que ésta se haya producido ni que, previsiblemente, vaya a ponerse en marcha con una masa crítica mínimamente significativa. Adicionalmente, apostó por fortalecer la actividad prestadora de las Diputaciones provinciales, cegando otros modelos de prestación y garantía de los servicios públicos de escala supramunicipal, sin que se hayan visto grandes beneficios como consecuencia de ello y, además, imponiendo una serie de tareas a estos órganos para las que en no pocos casos -provisión de los medios para la importante reforma administrativa impuesta por las reformas en materia de procedimiento electrónico derivadas de las leyes 39/2015 y 40/2015 en los municipios de menos de 20.000 habitantes- ya se están mostrando como francamente incompetentes. En el tercero de los aspectos referidos, apostó por un modelo de determinación de las competencias locales rígido y limitado, donde además se excluía la participación de las Comunidades Autónomas, que fue muy criticado doctrinalmente por erróneo, poco razonable y, además, contrario al reparto constitucional en materia de competencias, cuestiones que parecen todas haberse verificado con el paso del tiempo, incluyendo los pronunciamientos del Tribunal Constitucional ya intervenidos, dado que éste, en sus Sentencias 41/2016 y 111/2016, ha enmendado la plana al legislador de forma muy significativa en materia competencial. Tampoco en materia de financiación y suficiencia la reforma ha aportado, en la práctica, nada diferente a recortes: ni lograr una mejora apreciable en la garantía y autonomía de la financiación local ni perseguir una mejor distribución de los recursos, más redistributiva, eran objetivos en realidad de la misma, por lo que siguen siendo cuentas pendientes de nuestro régimen local. Por último, las reformas planteadas en las formas de prestación de los servicios públicos, destinadas en teoría a lograr una mayor eficiencia, no han tenido otro efecto jurídico que alentar la privatización de la prestación de los servicios públicos municipales, poniendo con ello en grave riesgo algunos servicios sociales. Ello en un momento en que, precisamente, la ciudadanía es más consciente tanto de la necesidad de los mismos y de lo peligroso de los recortes en un contexto de severísima crisis social como el que vivimos, como de las garantías asociadas a la prestación pública de los mismos. Por esta razón tiene sentido, aprovechando la experiencia acumulada, revisar las orientaciones de la reforma de 2013, analizar las causas de su fracaso y esbozar posibles soluciones a los retos todavía pendientes respecto de estos nucleares aspectos del diseño de nuestro gobierno local.

\section{AL HILO DEL MINIFUNDISMO MUNICIPAL EN ESPAÑA, DE LA NECESARIA REFORMA DE LA PLANTA LOCAL Y DEL TIPO DE ENTES DE CARÁCTER SUPRAMUNICIPAL QUE PODRÍA AYUDAR A MEJORAR LA EFICIENCIA DE LAS POLÍTICAS PÚBLICAS A ESCALA LOCAL}

Una crítica muy común, reiterada hasta la saciedad, a nuestro modelo de régimen local es la que se refiere al excesivo número de municipios existentes en España y sobre todo, y como inevitablemente consecuencia de ello, a su reducido tamaño. Suele ponerse de manifiesto que el número de municipios, unos 8.000 , se ha mantenido constante en las últimas décadas, sin que las normas postconstitucionales hayan favorecido o potenciado las fusiones de municipios (Dafflon, 2013), a diferencia de lo ocurrido en otros países de nuestro entorno como, por citar sólo algunos ejemplos significativos, Inglaterra, Dinamarca o Alemania (Schefold, 2012). Obsesivamente se apela al umbral de los 20.000 habitantes como el número mágico a partir de la cual los entes locales pasarían a ser eficientes y capaces de prestar servicios y se repite como un mantra la cifra de que en España sólo unos 400 municipios -esto es, un $5 \%$ del total- superan esta barrera. No obstante, ni el entorno comparado al que se apela frecuentemente pone de manifiesto una anomalía española tan dramática como suele comentarse ni es necesariamente cierto que un ente local no pueda funcionar y cumplir perfectamente todas o al menos muchas de sus funciones por debajo de los 20.000 habitantes, como por lo demás ha sido reiterado por quienes más han estudiado estas cuestiones de forma empírica (Lago Peñas y Martínez Vázquez, 2013).

Ello no obstante, la conclusión reiteradamente extraída por muchos, como ha sido defendido por ejemplo en esta Revista recientemente con muchos datos y de forma sin duda elocuente (Durán García, 2016), por acudir sólo al último de los ejemplos, es que el legislador debería tomar cartas en el asunto e imponer fusiones como, se argumenta, ha sido el caso en no pocos países de nuestro entorno. Tal fue, por lo demás, la solución que inicialmente plantearon los instigadores de la reforma 2013, si bien la LRSAL abandonó este planteamiento coactivo ante las reticencias que generaba incluso entre las bases locales del partido en el gobierno, optando finalmente por combinar como medidas de «racionalización» tanto las clásicas soluciones de incentivo económico de las fusio- 
nes -más bien modestos, por otro lado- como tratando de poner en marcha la recentralización de muchas de las competencias de los municipios de menos de 20.000 habitantes en las Diputaciones provinciales. Ambas medidas han resultado, a la postre, un fracaso.

Y no es de extrañar que así sea, dado que el debate queda descentrado si no se tiene en cuenta que el tamaño del municipio tiene más o menos importancia dependiendo, como es obvio, de su nivel competencial y de la flexibilidad de éste. Es decir, no genera los mismos problemas el minifundismo municipal si existen entes regionales potentes (como ocurre en España) que si no es el caso, como ocurre en Inglaterra o Dinamarca, por referirnos a los mismos ejemplos antes señalados, dado que las competencias de los municipios en el primero de los supuestos, inevitablemente, tenderán a ser menores. Asimismo, los problemas derivados del minifundismo municipal se minimizan de forma notable si hay estructuras de apoyo a escala más amplia y un modelo local flexible que permita la agrupación funcional de ciertos servicios o la gestión intercomunal de muchos intereses, como pasa por ejemplo en Francia, que conserva 40.000 municipios -5 veces más que en España, esto es, un $500 \%$ más, a pesar de contar únicamente con un 50\% más de población que nuestro país, Hertzog, 2012-, muchísimos de ellos con poblaciones reducidísimas, pero que está apostando decididamente por estructuras metropolitanas y de prestación de servicios en común que, a diferencia de lo ocurrido en España, han abandonado la lógica centralista de tratar de imponer un modelo igual a todo el país y apuestan por la diversidad funcional. $Y$ ello a pesar de que el Estado francés tiene una conocida fama, ganada a justo título, de adherir a una tradición más bien uniformizadora.

Es el caso también de la República Federal de Alemania, que cuenta en estos momentos con unos 12.000 municipios frente a los 8.000 españoles, lo que en proporción a la población de uno y otro país nos sitúa en una situación bastante semejante en este asunto del número de municipios que obsesiona tanto a los reformadores españoles. Donde sí hay notables diferencias entre España y Alemania es, de nuevo, en que en ese país sí se ha logrado una tendencia a la baja en el número de municipios por medio de fusiones incentivadas, reduciendo poco a poco, pero de forma constante, el minifundismo municipal y creando estructuras más potentes por medio de la eliminación de bastantes de los entes locales más pequeños e ineficientes. Ahora bien, ello se ha logrado con un notable impulso regional, no tanto de la Federación, y permitiendo una generosa variedad de aproximaciones dependiendo de los Länder. Algo que en España, dadas las diferencias de tipologías municipales y de tamaño de los municipios o en cuanto a la densidad de población de ciertas regiones, debiera ser tenido en cuenta: probablemente el tamaño municipal óptimo no es el mismo en zonas litorales muy pobladas que en áreas de interior con núcleos dispersos, alejados y muy poco poblados. Por todo ello quizás pareciera sensato, como por lo demás era la pretensión inicial del constituyente -el art. 148.1.2. ${ }^{2} \mathrm{CE}$ es bastante significativo al respecto-, dejar en esta materia un amplio protagonismo a las Comunidades Autónomas, incentivando y ofreciendo estímulos económicos, en su caso, pero permitiendo que sean ellas las que tengan el verdadero protagonismo a la hora de diseñar el nuevo mapa de la planta local necesario para afrontar en las mejores condiciones las necesidades sociales y económicas de la población en el actual contexto.

Es decir, la dirección correcta para la superación de los problemas del minifundismo municipal va justo en una línea contraria a la reforma local de 2013. Deberíamos afrontar este reto asumiendo las bondades de la diversidad y dejando que fueran las Comunidades Autónomas, como por otro lado está claramente en el espíritu de la Constitución, las que actualicen y reorganicen la planta local. Para ello es esencial que, cuanto antes, la norma básica de régimen local dé un paso atrás, elimine sus múltiples preceptos que gratuita e innecesariamente imponen modelos uniformes y reapodere a la legislación autonómica de la capacidad para diversificar funcionalmente el modelo local a partir de las necesidad u orientaciones políticas, o visiones de cómo lograr una mayor eficiencia, de cada región. Algo que, además, permitiría y alentaría la experimentación y la diversificación, así como el abandono de modelos uniformes, en la línea de lo que también es común en Europa. Experimentación que, hasta la fecha, ha brillado por su ausencia en España, en gran parte, por las enormes limitaciones que impone una Ley Reguladora de las Bases del Régimen Local que va mucho más allá de lo que debiera, tendencia que tanto la reforma de 2013 como sentencias como la conocida STC 31/2010 recaída sobre el Estatuto catalán de 2006, de claro cariz recentralizador también en esta materia, refuerzan no sólo innecesaria y erróneamente sino, también, en un sentido contrario a lo que es la pauta dominante allende nuestras fronteras, donde se tiene claro que la diversidad es esencial para lograr mejoras en la eficiencia por permitir una mayor adaptación a las realidades diferentes complejas y por permitir, adicionalmente, la experimentación y emulación.

Esta reflexión, por ello, tiene también mucho que ver con cómo se establecen, en paralelo a municipios poco a poco más eficientes y de mayor tamaño por distintas vías pero preferiblemente con un trato generoso con la diversidad y por vía incentivada, mecanismos de garantía de ciertos servicios y prestaciones de tipo supramunicipal. En este sentido, también la reforma de 2013 se ha alejado significativamente de la pauta europea, lo que de nuevo 
debiera dar queé pensar. Recordemos que, y también como consecuencia sin duda de las presiones europeas comunes a toda la Europa mediterránea, nuestra reforma local ha intervenido en paralelo a un proceso de reforma de los diversos niveles de acción pública en países como Francia o Italia, aún en proceso. Sin embargo, y a diferencia de lo ocurrido en España, en esos países la reforma no se ha limitado sólo a la esfera local, ni siquiera se ha centrado en ella, sino que ha apostado también por un replanteamiento profundo de las estructuras intermedias, tanto regionales como, sobre todo, equivalentes a nuestras provinciales, cuya subsistencia se pone en cuestión -a diferencia de lo ocurrido aquí- tanto en Italia (Morcillo Moreno, 2014) como incluso en Francia, cuna de las mismas, pues el modelo tiene su origen en la figura del département revolucionario. En este caso, cuestionados hace tiempo como entes funcionalmente poco eficaces (Bazoche, 2008), finalmente parecen en trance de ser reformados profundamente, cuando no liquidados con la propuesta del Gobierno Valls para su eliminación progresiva. En efecto, y en el marco de la reforma de las regiones ya acometida, esta supresión está ya programada para finales de esta década, aunque aún sometida a debate por la oposición de parte de la derecha francesa a la medida. Frente a las estructuras tradicionales, las reformas apuestan por ceder protagonismo tanto a las regiones como a diseños de prestación intercomunal o metropolitanas, normalmente voluntarias pero claramente incentivadas -tanto económicamente como sumando competencias a estas estructuras cuando son efectivamente creadas y puestas en marcha-.

Un aspecto, como puede comprobarse muy llamativo, de la reforma española de 2013 es, en este y otros puntos, su clara desconexión con las tendencias al uso en el resto en Europa. Y ello a pesar de la retórica al uso, que trató en su momento de poner en valor la supuesta coordinación de la reforma española con las dinámicas que se habrían supuestamente generalizado allende los Pirineos. Resulta absolutamente increíble que existiendo numerosos trabajos de gran calidad sobre el régimen local en los países de la UE -algunos de ellos editados por el propio Instituto Nacional de Administración Pública (Moreno Molina, 2012), y que por ello debieran ser cercanos a quienes han promovido la LRSAL-, así como otros, como el muy interesante estudio del equipo dirigido por Francisco Velasco (2010) sobre las reformas del régimen local en los Estados de tradición federal, que se acometa un estudio de estas cuestiones sin la más mínima valoración económica o funcional -al estilo de la que puede encontrarse en la obra ya mencionada de Lago Peñas y Menéndez Vázquez de 2013- y sin la más mínima preocupación por estudiar en profundidad cuáles son las soluciones que de verdad se están imponiendo en nuestro entorno tanto geográfica como jurídicamente más cercano.

Frente a modelos flexibles y diversos, con mucho fomento de la coordinación y de la voluntariedad e incentivo de la experimentación en la base, aquí se pretende imponer un diseño homogéneo decidido desde arriba; frente a una apuesta por la subsidiariedad y lo local, patente en toda Europa -y aunque resulte contraintuitivo también en los casos de países que han fusionado municipios... para precisamente poder dotarlos de más competencias-, aquí se opta por la estructura provincial y la jerarquización en la provisión de servicios; frente a la intercomunalidad incentivada y la respuesta compleja a un mapa diverso, aquí el Estado sigue pretendiendo dar una receta unitaria para todo el territorio. No puede, en definitiva, encontrarse un ejemplo de reforma peor diseñada que la de la planta local que se encierra en la ley local española de 2013.

Por esta razón, no es de extrañar su completo fracaso en este punto. El legislador ha pretendido aplicar recetas antiguas para afrontar un problema que ciertamente se arrastra desde hace años pero que se proyecta sobre el presente y el futuro: el minifundismo municipal español y la evidente inadecuación de demasiadas Administraciones minúsculas para hacer frente a muchos de los retos para los que en materia prestacional las complejas sociedades de nuestros tiempos demandan una respuesta. Pero en lugar de experimentar con soluciones modernas y mirarnos en el espejo europeo, en lugar de permitir a las Comunidades Autónomas ir más allá con algunos de los modelos de agrupación para la gestión en niveles intermedios ya conocidos desde hace años y aplicados por toda Europa, se opta por un sorprendente retorno, si no a 1833 y Javier de Burgos -aunque el mapa mental de España que tenía en la cabeza el legislador sea sin duda ése, como es patente-, sí a las soluciones de finales de principios de del siglo XIX: unos municipios capitidisminuidos y con competencias escasísimas en comparación con sus equivalentes europeos que, además, no se podrían incrementar; unas Diputaciones provinciales a las que se aspira a convertir, a pesar de sus múltiples y manifiestos problemas, en la Administración local por excelencia de la proximidad, incrementando su peso; una estructura idéntica en todo el territorio español, con independencia de sus condiciones económicas, demográficas, sociales, geográficas...; y unas Comunidades Autónomas que nada tendrían que decir ni que oponer a estas pretensiones, porque para la LRSAL de 2013 el papel ordenador del Estado cubre prácticamente todo y no ha lugar a que territorialmente se pueda mejorar el modelo, dar más competencias o, ni siquiera, a participar en determinar cómo se prestan a escala local las competencias y atribuciones propias de cada Comunidad -conviene repetir y detenernos en el adjetivo- Autónoma. Se trata de otro grosero error de la reforma que explica también, en parte, su triste final. 


\section{SOBRE POR QUÉ LAS COMUNIDADES AUTÓNOMAS DEBIERAN PODER TENER MUCHO QUE DECIR EN LA DETERMINACIÓN DEL RÉGIMEN LOCAL DE SUS MUNICIPIOS, TANTO A NIVEL ORGANIZATIVO COMO COMPETENCIAL}

El asentamiento del modelo constitucional de régimen local español tal y como fue concretado desde 1985 por la LRBRL y todo su desarrollo, por mucho que en general y globalmente exitoso, ha convivido, sin embargo, con una crítica muy común, especialmente desde sectores más municipalistas, respecto de las escasas competencias municipales que, a la postre, han acabado consolidándose en favor de los municipios, que se entiende que por lo general son muchas menos tanto de las que podrían gestionar una gran número de municipios, por un lado; como de las que sería deseable que tuvieran reconocidas, por otro. Estas críticas han sido numerosas y vienen de antiguo, aunque se agudizaron tras la gran transferencia de competencias a favor de las Comunidades Autónomas de régimen general que se produce a lo largo de la década de los noventa (por ejemplo, Rodríguez Arana-Muñoz, 2002-2003). Han resaltado, así, cómo el reparto territorial del poder, excesivamente centrado en la pugna competencial entre el Estado y las Comunidades Autónomas, habría dejado de lado a los municipios.

A este respecto, es cierto que la aparición de las Comunidades Autónomas, con el desplazamiento de muchas competencias tradicionalmente estatales a la escala regional -si bien, a la hora de la verdad, con menos intensidad de lo que se suele decir porque el Estado retiene mucha capacidad de determinación en no pocos ámbitos-, ha contribuido a relegar a un segundo término a los municipios en lo que se refiere a su nivel competencial. Se trata de un fenómeno que se debería analizar en dos planos conectados pero que conviene diferenciar. Por un lado, el estrictamente relacionado con el reparto de competencias a diferentes niveles y la reflexión sobre cuáles son los ámbitos de decisión óptimos para poner en marcha toda una serie de políticas públicas, cuestión que tiene que ver con la funcionalidad y diseño de la planta administrativa y los niveles óptimos para una mejor gestión. En este punto, resulta obvio que la aparición de las Comunidades Autónomas tiende a concentrar en ellas ciertos servicios y prestaciones que requieren de cierta red o que presentan economías de escala -piénsese en los servicios sanitarios o educativos- pero que, en países sin niveles regionales potentes y con municipios de mayor tamaño, en muchas ocasiones sí son asumidos por los municipios. Por otro lado, en un plano estrictamente político, es también cierto que la mayor potencia representativa de las Comunidades Autónomas, así como su relativa novedad tras la Constitución de 1978, ha centrado el debate sobre el reparto Estado-Comunidades Autónomas y los conflictos surgidos en torno a las visiones más centralistas y las más partidarias de la descentralización, quedando oscurecido el debate sobre las competencias municipales (Boix Palop, 2013). Ello fue así, al menos, en los primeros años. Aunque también es cierto que la crisis económica y social de esta última década y su intensidad sin precedentes desde el final de la II Guerra Mundial está ayudando a poner de nuevo en valor la importancia de la labor local de proximidad para mejorar las condiciones de vida de los ciudadanos y defenderlos frente a la exclusión, así como para dotarlos de una verdadera igualdad de oportunidades en muchos ámbitos, para lo cual el amplio desarrollo de competencias y políticas locales resulta esencial, y muy especialmente en las grandes aglomeraciones urbanas más castigadas por la crisis (Romero, 2015).

Sin embargo, ninguna de estas dos dinámicas es inevitable ni ha de conducir necesariamente a desplazar y marginar a los municipios. Una manera de evitarlo es, justamente, permitir un gran protagonismo a las Comunidades Autónomas a la hora de definir, como mayor o menor ambición según los casos, el ámbito competencial de sus entes locales, tanto aisladamente considerados como en las diferentes modalidades de prestación conjunta de servicios que, mancomunada o consorciadamente, de forma intercomunal, comarcal o metropolitana, puedan imaginarse. Algo que no ha sido posible hasta la fecha y que la reforma de 2013 pretendió hacer si cabe más difícil. Ha de ser tenido en cuenta, en este sentido, que el régimen local español derivado de la LRBRL ha tendido tradicionalmente a la uniformidad, atribuyendo sustancialmente las mismas competencias y responsabilidades a todos los municipios con independencia de su tamaño, variando únicamente la obligación -que no la posibilidad- de prestar ciertos servicios locales; así como ha establecido un modelo organizativo muy similar para todos ellos. Sólo con el paso de los años se ha introducido una leve diferenciación, de tipo organizativo, para grandes municipios -la Ley 57/2003 reformó en este sentido la LRBRL ya muy tardíamente, para establecer ciertas normas esencialmente organizativas y orgánicas diferenciadas, con equipos locales más fuertes y dinámicas de control por parte del pleno algo más «parlamentarias», así como con medidas de desconcentración administrativa en distritos por lo demás muy tímidamente aplicadas-. Lo cierto, sin embargo, es que la reforma, aunque generó mucha más flexibilidad y algunas posibilidades de diferenciación estructural (García Rubio, 2011), requiere de mucha voluntad política para, con base únicamente en ella, desplegar políticas locales claramente ambiciosas. Tampoco supuso diferencias competenciales relevantes más allá de las tradicionales. Los municipios españoles, todos ellos, han seguido, en definitiva, dependiendo de una norma básica que es un corsé bastante rígido y uniformizador. Lo cual a su vez tiene efectos sobre el debate competencial. A menos posibilidades de diferenciación y menor flexibilidad del modelo, 
mayor es la tendencia a evitar la generosidad con los municipios en el plano competencial, pues descentralizar en favor de éstos supondría hacerlo a favor de todos, incluyendo también a municipios muy pequeños.

Adicionalmente, ha de ser señalado que este debate tampoco ha contado con una influencia autonómica a favor de la descentralización. A pesar de que la forma tradicional de entender el modelo LRBRL -que posteriormente veremos que la reforma local de 2013 pone abiertamente en cuestión y somete a una gran polémica- consideraba que las competencias atribuidas por la ley estatal eran mínimos que reflejaban la garantía institucional de la autonomía local pero que en todo caso eran susceptibles de ser superados y ampliados por la legislación autonómica en el ámbito competencial que le es propio, lo cierto es que las leyes locales autonómicas generales, incluyendo las más avanzadas -Andalucía, Cataluña, Comunidad Valenciana-, han sido más deudoras de la ley estatal que innovadoras en este campo. Sólo la legislación sectorial autonómica ha sido algo más generosa, pero normalmente siempre asignando a los entes locales funciones subsidiarias y de ejecución.

Por todo ello, el debate sobre la necesaria «segunda descentralización», si bien siempre ha estado presente, nunca lo ha sido de forma excesivamente intensa ni ha logrado ampliar las competencias municipales de forma sustancial (Rodríguez Arana-Muñoz, 2002-2003). El Ilamado Pacto Local trabajosamente logrado a final de la década de los 90 del siglo pasado para reforzar la autonomía local por medio de la reforma de la LRBRL, sin ir más lejos, acabó más centrado en establecer mecanismos de defensa de las competencias ya existentes que en una ampliación significativa de las mismas -por medio de la LO 7/1999 se establece la posibilidad de que cierto número, considerable, de ayuntamientos puedan plantear ante el Tribunal Constitucional conflictos en defensa de la autonomía local ante posibles invasiones de competencias, como por ejemplo el que ha sido planteado, aún no resuelto, por la supuesta invasión de la misma derivada de la reforma de la LRBRL de 2013-.

No ha sido hasta muy recientemente, en un contexto de crisis institucional muy acusado, cuando las demandas de descentralización a favor de los municipios se han hecho algo más concretas y se han ido extendiendo, normalmente vinculadas a las exigencias de mayor transparencia, participación ciudadanía y cercanía de la población a la toma de decisiones, que tendencialmente apoyan, de la mano del principio de subsidiariedad, que ese acercamiento se produzca ampliando la capacidad competencial de los municipios (Romero y Boix, 2015). Debate que, sin embargo, no se ha plasmado por el momento en reformas legales. Al contrario, y como se ha dicho, la reforma operada por la LRSAL en 2013 en el texto de la LRBRL ha ido, más bien, en sentido contrario, de la mano de la tradicional justificación que pone el foco en los municipios pequeños y su incapacidad para gestionar competencias ambiciosas (Almeida Cerreda, 2013: 79-88).

Resulta interesante resaltar, en este punto, que la LRSAL, en efecto, va en una dirección radicalmente contraria a la aquí preconizada y que, como ha señalado unánimemente la doctrina que se ha ocupado con detenimiento de esta cuestión (Velasco Caballero, 2014), lo ha hecho con una vocación que ha combinado de manera muy potente recentralización a favor del Estado y jibarización de los poderes de proximidad. La reforma reduce las competencias municipales y, además, pretende fijar su exacta extensión rígida e indeleblemente en la ley básica estatal, de manera que de ahí no se pueda, en ningún caso, pasar y de modo que los municipios no puedan en absoluto ver ampliado su ámbito competencial (Arenilla Sáez, 2014; Forcadell Esteller, 2014). Para ello la ley local de 2013 no sólo ha de uniformizar y hacerlo en este sentido limitador sino, además, combinar esta intención con una recentralización de la concepción de las competencias en materia local, que pasan a ser entendidas como estatales incluso para definir qué pueden o no las Comunidades Autónomas determinar que pase a ser competencia municipal. La LRSAL aspira incluso, como es sabido, a impedir a las normas sectoriales autonómicas reguladoras del ejercicio de sus competencias exclusivas la asignación de competencias ejecutivas en estos campos a los entes locales que vayan más allá de lo previsto por la norma estatal. Se trata de un objetivo que no sólo explica, por lo errado y desconocedor de la realidad local del país, el fracaso aplicativo de la reforma sino que, además, demuestra una enorme incomprensión respecto de las bases constitucionales del modelo de reparto del poder implantado, con el Estado autonómico, por la Constitución de 1978.

De hecho, el no siempre en exceso beligerante Tribunal Constitucional español así lo ha declarado sin ambages en sus pronunciamientos sobre la Ley 27/2013, dos hasta la fecha -SSTC 41/2016 y 111/2016, especialmente en el primero de ellos-, que contienen una enmienda a la totalidad, en este punto, a la visión constitucional expresada por el legislador español, asestando un golpe definitivo a las tesis que pretendían homogeneizar totalmente nuestro régimen local (sobre estas sentencias, Medina Alcoz, 2016). Lo hace en la medida en que sencillamente, reconoce que allí donde las competencias sean autonómicas corresponderá, lógicamente, a las Comunidades Autónomas decidir cómo se organiza la prestación de los correspondientes servicios y políticas públicas. Una regla sencilla y clara que resulta incomprensible que al legislador estatal de 2013 le costara tanto interiorizar. La STC 41/2016 explica con claridad que el Estado «sólo podrá atribuir competencias locales específicas, o prohibir que éstas se desarrollen en el nivel local, cuando tenga la competencia en la materia o sector de que se trate», por lo 
que «(e)n materias de competencia autonómica, sólo las Comunidades Autónomas pueden atribuir competencias locales o prohibir que el nivel local las desarrolle». Se trata de una regla, como se dice, extraordinariamente clara y aparentemente sencilla de aplicar que, sin embargo, la reforma de 2013 desconoció totalmente, tanto a la hora de ordenar cómo prestar ciertas competencias en concreto -para más inri, incidiendo en algunas competencias típicamente autonómicas como sanidad, educación, servicios sociales...- como para establecer un modelo de reparto de las competencias municipales que, como ya se ha expuesto -e innovando sobre lo que era la tradición española en la materia desde la Ley Reguladora de las Bases del Régimen Local de 1985-, concebía el listado de competencias atribuida por la misma a los entes locales como exhaustivo y no susceptible de ninguna adición autonómica, algo que de modo evidente, aplicando la doctrina del Tribunal Constitucional tradicional ahora reiterada, decae naturalmente.

Y es que es lo cierto que la STC 41/2016, técnicamente muy solvente, no es particularmente novedosa, como había señalado la doctrina antes de la decisión del Tribunal (Alonso Mas, 2014; Boix Palop, 2014). Nada de lo que señala es sorprendente $y$, de hecho, lo llamativo es hasta qué punto los redactores de la ley, el gobierno de entonces, del Partido popular, así como los parlamentarios que apoyaron la ley -que no fueron sólo los de la mayoría del gobierno- y parte de la doctrina fueron capaces de obviar una consolidada jurisprudencia constitucional, que el Tribunal desgrana en su sentencia -el extenso FJ $3 .{ }^{\circ}$ es un gran resumen, completado con el FJ $4 .^{\circ}$ y el FJ 9..$^{\circ}$, que hacía bastante evidente que la reforma propuesta y su pretensión de desapoderar a las Comunidades Autónomas en materia de régimen local no era, sencillamente, constitucional. Y ello por mucho que este Tribunal, que no tiene más remedio que afirmar la inconstitucionalidad de esas partes de la ley, no sea particularmente hostil a la idea de recentralización. No lo es desde hace años y tampoco lo es en esta sentencia: admite sin mayor problema una importante capacidad del Estado para intervenir por medio de su legislación básica y, por ejemplo -FJ $5 .^{\circ}$ y $6 .^{\circ}-$, para redelimitar la competencia autonómica en materia de planta local; también admite sin mayor problema que el Estado imponga nuevas exigencias de todo tipo y especialmente financieras a entes locales asociativos y entidades locales menores; $y$, en general, avanza en la línea ya muy consolidada por el propio Tribunal de admitir que las competencias horizontales en favor del Estado se pueden interpretar de forma muy generosa, dando así carta de naturaleza definitiva a que el art. $149.14 .{ }^{a}$ CE otorgue al Estado la competencia en materia de «Hacienda y Deuda del Estado» como título para intervenir de manera amplísima sobre otras Administraciones desde el momento en que se reconoce que pueda estar en cuestión, aunque sea lejanamente, la estabilidad financiera de nuestro sector público. Apelando a todas estas razones salva casi todos los instrumentos de la ley 27/2013 que reformaron la LRBRL estableciendo nuevas reglas y procedimientos que se imponían a los entes locales (y a las Comunidades Autónomas) con la excusa de lograr ahorros, control del gasto y «racionalización». Pero una cosa es admitir todo eso, como viene siendo frecuente, y otra muy distinta obviar que eliminar la capacidad autonómica de autoorganización respecto de sus competencias exclusivas es atentar directamente contra la idea misma de autonomía política constitucionalmente garantizada.

Por ello la sentencia, tras establecer la doctrina general al respecto en el FJ 9. ${ }^{\circ}$ ya citado de la STC 41/2016, interpreta la reforma de la LRBRL en un sentido que es radicalmente contrario al que pretendían los impulsores de la norma -o al que señaló, en su momento, también incomprensiblemente, el Consejo de Estado-:

«Debe, pues, excluirse la interpretación de que los municipios solo pueden obtener competencias propias en las materias enumeradas en el art. 25.2 LBRL. Si el Estado quisiera apoyarse en el art. 149.1.18 CE para interferir de modo tan penetrante en las competencias de las Comunidades Autónomas (prohibiendo con carácter general que estas atribuyan competencias propias a los municipios de su ámbito territorial en cualesquiera otras materias), tendría que haberlo establecido expresa o inequívocamente. Por lo demás, semejante prohibición, indiscriminada y general, sería manifiestamente invasiva de las competencias de las Comunidades Autónomas. Consecuentemente, en los ámbitos excluidos del listado del art. 25.2 LBRL, las Comunidades Autónomas pueden decidir si, y hasta qué punto, los municipios deben tener competencias propias, pero sujetándose a las exigencias de los apartados 3, 4 y 5 del art. 25 LBRL; además de a las garantías de autonomía local previstas en la Constitución y, en su caso, en los Estatutos de Autonomía» (FJ 10. ${ }^{\circ}$.

En definitiva, la pretensión estatal de restringir las competencias locales a las que la propia norma estatal determinarla sin posibilidad de ampliación de las mismas por parte de las Comunidades Autónomas, no es constitucional. Pero más allá de la valoración jurídica de la reforma de 2013 en este punto, resulta también muy interesante recordar que su fracaso no lo ha sido sólo en el plano técnico. Las Comunidades Autónomas, conscientes tanto de la incorrección jurídica del planteamiento como de sus muy negativos efectos, no se han sentido concernidas por la limitación y no sólo han aprobado desde 2013 una serie de normas (Velasco Caballero, 2015), tanto legales como 
reglamentarias, dejándolo meridianamente claro y declarando que consideraban en vigor aquellas normas autonómicas que en el pasado habían ampliado competencialmente las capacidades municipales en aquellas materias -sociales- donde la reforma de 2013 pretendía limitarlas -normas que quedan perfectamente legitimadas tras la STC 41/2016- sino que, además, han entendido plenamente en vigor en todo momento toda su legislación, ya sea la sectorial, ya la general en materia de régimen local, que ampliaba con carácter previo a la reforma de 2013 de la RBRL las competencias locales, sin que por lo demás el Estado haya pretendido impugnarlas con excesivo afán. Adicionalmente, la discusión respecto del entendimiento de las limitaciones sobre las competencias impropias que pretendió imponer la LRSAL -es conocida su pretensión de impedir en primera instancia, o dificultar mucho su ejercicio por parte de poderes locales, en una segunda, de cualquier competencia que no esté expresamente atribuida a los mismos y que por ello se considera «impropia»- y su desleída aplicación hasta el momento también van en la misma línea: en la práctica se ha permitido a Comunidades Autónomas y entes locales seguir como prestando los servicios que ya prestaban antes de 2013, si así lo han considerado, y con la única e importante salvedad de que en todo caso hayan de asegurar que la prestación de éstos no pone en riesgo la estabilidad económica del municipio.

Es decir, incluso antes de la STC 41/2016, y haciendo gala de cierta imaginación, flexibilidad y voluntad de consolidar niveles competenciales, así como de un apreciable grado de coraje jurídico, las Comunidades Autónomas y Entes Locales había logrado dejar la reforma, a efectos prácticos, en un estado comatoso -al menos, respecto de este plano competencial- (Navarro Rodríguez y Zafra Víctor, 2014). Y lo estaba porque social y políticamente el acuerdo entre los diversos actores sobre su carácter negativo era casi total y porque se consideraba que no aspiraba, al menos en este punto, en modo alguno a «racionalizar» sino que, simplemente, obligaba a recortar -sobre todo, prestaciones sociales- y nada más. Es la reacción de la sociedad y de las Administraciones autonómicas y locales la que pone en cuestión la ley, primero, en el plano social y aplicativo respecto de su pretensión de limitar muy notablemente la capacidad de prestación de los municipios. El Tribunal Constitucional, simplemente, se ha militado a darle con posterioridad a esa reacción la jurídica extremaunción.

Con todo, y más allá de lo señalado a la postre el Tribunal Constitucional sobre esta cuestión, hay ciertas incertidumbres políticas todavía por despejar. A día de hoy, aunque ya sabemos qué tipo de reforma no es sólo inconstitucional sino que además es radicalmente rechazada por la mayoría de los actores implicados, nos falta saber qué modelo de reforma podría ser el más adecuado para afrontar los retos presentes y futuros a que ha de dar respuesta el gobierno local de sociedades diversas, complejas y con grupos sociales crecientemente alejados de los estándares de riqueza y posibilidades del conjunto de la sociedad. En coherencia con lo señalado en el apartado anterior, porque además sin un entendimiento en paralelo del mismo es imposible aspirar a su puesta en marcha, hay que señalar que una reforma futura de la LRBRL que aspire a mejorar la eficiencia de nuestras Administraciones locales debiera asumir con naturalidad un importante grado de descentralización en este punto y, volviendo al entendimiento de que su función es establecer la garantía de unos mínimos competenciales que aseguren la autonomía local, permitir e incluso alentar la mayor posibilidad de protagonismo autonómico a la hora de ampliar estos mínimos competenciales. Los efectos sobre la responsabilización de los actores y a la hora de alentar la ya referida y por tantos reclamada «segunda descentralización» serían inmediatos y, a buen seguros, muy positivos. Sobre todo si se completa con una reforma sensata de la financiación local y con una mayor atención a las consecuencias sociales de las reformas.

\section{EN TORNO A LAS INSUFICIENCIAS DE LA FINANCIACIÓN LOCAL, ESPECIALMENTE EN LO QUE SE REFIERE A SU CAPACIDAD REDISTRIBUTIVA, Y OTRAS CONSECUENCIAS SOCIALES QUE TODA BUENA REFORMA LOCAL DEBIERA TENER EN CUENTA}

La reforma de 2013 se realizó en total desconexión con cualquier consideración referida ala financiación local que, quizás por considerarse una cuestión conflictiva en medio de un contexto de crisis que incitaba, en todo caso, a recortes más que a alegrías, se prefirió aislar del debate. Sin embargo, una reforma que afronte los verdaderos retos de futuro del diseño de nuestros entes locales, en coordinación con los factores ya señalados, no puede no atender a la influencia que este aspecto tiene sobre los demás. De hecho, un elemento de debate político que ha acompañado a nuestro modelo de régimen local estos años es la crítica, casi ritual, al modelo de financiación local, que tradicionalmente se ha caracterizado de muy insuficiente. Sin embargo, nada de su estructura ni de los incentivos que directa e indirectamente genera fue analizado junto a la reforma local de 2013, lo que es también manifiesta prueba de la peculiar visión de los instigadores de la misma, que parecen creer que las cuestiones de planta, regulación y eficiencia en la prestación pueden reformarse sin atender a este otro aspecto más que en la dimensión de recortar. Porque, en efecto, la única reflexión sobre la «sostenibilidad» de los entes locales españoles contenida en la LRSAL era la derivada de la idea de que, si se contenían las funciones y ambiciones prestacionales de los municipios, esto es, si re recortaba, ello redundaría necesariamente, como 
es lógico, en menos gasto y, con ello, en una mejor situación financiera. Como es manifiesto, se trata de una aproximación de una pobreza conceptual inasumible para cualquier persona que aspire a plantear cómo habría de ser nuestro régimen local del futuro.

Como punto de partida hemos de asumir el hecho de que toda la financiación de las Administraciones españolas que no son Administración del Estado es manifiestamente mejorable, como ponen de manifiesto todos los indicadores internos y comparados. También hemos de tener presente, además, que las orientaciones de este trabajo, que incrementarían las responsabilidades de los entes locales deberían por ello, como es obvio e inevitable, ir acompañadas de los mecanismos para proveer los necesarios medios financieros para hacerlas posibles, puesto que con la actual financiación sería sencillamente imposible acometerlas. Ahora bien, a pesar de esas premisas, hay que señalar igualmente que no todo es negativo en el actual modelo de financiación de nuestros entes locales. Junto a la habitual crítica por su insuficiencia es interesante, también, resaltar algunos aspectos positivos que suelen pasar inadvertidos. En primer lugar, que en realidad el sistema permitiría a nuestro juicio sin mayores problemas, con la debida voluntad política, el desarrollo de diferentes políticas tributarias por parte de las corporaciones locales. Además, se pueden apuntar mejoras sencillas que lo harían más flexible y adaptable (Lago Peñas y Martínez Vázquez, 2014). Por ejemplo, es un hecho que en la financiación local actual, a día de hoy, hay un gran peso de tributos, esencialmente impuestos directos, cuya cuantía depende de los propios ayuntamientos. Simplemente de esa constatación se deducen claras consecuencias en materia de capacidad política y corresponsabilidad fiscal que son, a mi juicio, más dignas de elogio que de crítica. Y que, por cierto, podrían inspirar una reorientación del sistema de financiación autonómico, donde siguen primando, por el contrario, numerosos incentivos a la no corresponsabilidad fiscal.

A grandes rasgos, el modelo de financiación local, del que nuestra Constitución simplemente dice que ha de ser establecido de forma que garantice la referida autonomía local y la suficiencia de recursos sin mayores precisiones ni garantías -lo que sí es ciertamente criticable-, ha sido también muy estable en sus fundamentos, por mucho que la Ley de Haciendas Locales haya sido modificada con frecuencia. La financiación local en nuestro país se caracteriza, así, por la combinación de tributos propios de los entes locales -esencialmente el Impuesto de Actividades Económicas, cuya importancia se ha visto reducida en los últimos años; el Impuesto de Bienes Inmuebles que grava la propiedad inmobiliaria; y los diversos impuestos relacionados con los vehículos a motor; también los indirectos derivados de la construcción- y las diversas tasas y precios públicos que recaudan por el empleo de bienes o servicios municipales, completados con la participación en impuestos estatales y autonómicos, que el Estado y las Comunidades Autónomas redistribuyen.

Las consecuencias de este modelo, ya se ha dicho, han sido tradicionalmente muy cuestionadas. En primer lugar, quede reiterado de nuevo, por la insuficiencia de los ingresos que se predica del mismo. Esta insuficiencia, con todo, podría ser matizada a la luz de ciertas evidencias: como es sabido, los municipios españoles son la Administración pública menos endeudada y con mayor equilibrio presupuestario -de hecho, las únicas que globalmente han logrado alcanzar superávit en los últimos años, Carbonell Porras, 2013: 17-22; Almeida Cerreda, 75-78-; adicionalmente, y a la luz del debate en torno a las competencias municipales derivado de la reforma de 2013, es claro que esta situación se ha alcanzado a pesar de que los municipios están prestando no sólo aquellos servicios que estricta y legalmente les corresponden sino, en muchos casos, también otros muchos que los vecinos les demandan (Almeida Cerreda, 2013: 72-75). Quizás la financiación municipal en España es insuficiente comparada con otros modelos comparados y en relación a las muchas cosas que podrían realizar los entes locales en un marco competencial más generoso, pero no parece que lo sea tanto en el contexto concreto en que nos movemos -por ejemplo, si la comparamos con la lamentabilísima financiación de algunas Comunidades Autónomas-.

Una crítica adicional que ha recibido el modelo es que los ingresos municipales así definidos son, por una parte, muy dependientes de la coyuntura económica -algo que, por lo demás, ocurre con casi cualquier tributo y que, de hecho, es dudoso que por ejemplo sea el caso con los impuestos que gravan la propiedad- $y$, por otra, que conlleva incentivos perversos en los entes locales, esencialmente asociados al urbanismo y al ciclo inmobiliario, que generan muchos ingresos a corto plazo asociados a la transformación urbana pero a cambio hacen que aumenten las responsabilidades y gastos a medio y largo plazo a que habrá de hacer frente la corporación (Romero, 2015).

Por último, y aunque no suele ponerse tanto de manifiesto frente a las dos críticas anteriormente referidas, el modelo de financiación municipal español es muy poco redistributivo, esto es, no matiza las diferencias entre municipios ricos y pobres o, más bien, municipios con población de más renta o de menos. Normalmente, los municipios con poblaciones en situaciones socioeconómicas más duras generan muchos menos ingresos gravados por tributos municipales y, por otra parte, la participación en tributos estatales y autonómicos se distribuye simplemente a partir de criterios poblacionales, lo que matiza un poco la desigualdad pero ni mucho menos la logra compensar del todo de forma satisfactoria. A diferencia de lo que ocurre con nuestro modelo de financiación 
autonómica, donde las transferencias entre unas Comunidades Autónomas y otras son considerables -y por ello muy criticadas desde ciertos ámbitos, no tanto en cuanto a este efecto como por su magnitud y lo poco ajustadas que están a las necesidades reales de solidaridad (Bel, 2013)-, la distribución de recursos estatales a los municipios, cuando se da -los municipios de mayor población viven un poco al margen de la misma, pues participan menos del fondo de redistribución a partir de criterios poblacionales- depende muy mecánicamente del número de habitantes de cada municipio. El efecto global es que los municipios «ricos», ya sea porque lo es globalmente su población en conjunto considerada o por tener en su término municipal ciertas industrias o actividades generadoras de muchas rentas, tienen una disponibilidad presupuestaria por habitante muy superior a la de otros entes locales.

Pues bien, estos factores han de ser tenidos en cuenta, máxime si, a la luz de la presente crisis económica y sus consecuencias, no podemos ser sino cada vez más conscientes de hasta qué punto la actividad prestacional local en materia de servicios sociales constituye la primera y más esencial red de seguridad para los más desfavorecidos. Únicamente a partir de una financiación no sólo generosa y adecuada a unas mayores responsabilidades de los entes locales sino también más redistributiva se podrá hacer frente satisfactoriamente a ese reto. La financiación y cómo se distribuye y redistribuye está íntimamente imbricada con las efectivas posibilidades de que las políticas locales cumplan plenamente con sus objetivos en un Estado social. También lo están con la efectiva posibilidad de que las herramientas jurídicas y el marco normativo en que han de ser desplegadas estas políticas permita la necesaria adaptabilidad al cambio de prioridades políticas.

Conviene en este punto resaltar la importancia de estos factores, y muy especialmente de la referida orientación, para el correcto despliegue de políticas ambiciosas en materias como el desarrollo local o las políticas sociales de base local y, muy especialmente, su radical necesidad e importancia en el actual contexto de crisis económica y social. Una crisis multifactorial que, como ha resaltado Joan Romero (2015), tiene en la ciudad uno de sus focos y en las políticas locales correctamente orientadas, financiadas y desarrolladas, una de las más importantes herramientas para combatirla. La importancia creciente de las aglomeraciones urbanas y su complejidad dotan a las decisiones en estos ámbitos de una capital importancia política. De ellas dependen en gran medida la salida de la crisis o, más bien, que esta salida lo sea para todos y en la mejor de las condiciones posibles o, por el contrario, dejando atrás desigualdades cada vez más duras y lacerantes. A estos efectos, y evaluadas las necesidades y determinadas las políticas de desarrollo local y social (Uceda y Martínez, 2015) imprescindibles, el Derecho ha de ser instrumento y marco que permita su desarrollo, para lo cual hemos de emplear los instrumentos de que nos dota de la manera más adecuada posible. Es muy dudoso, por ello, que la reforma local de 2013 sea un buen ejemplo de la orientación a seguir, dadas las negativas consecuencias sociales que la misma habría provocado -y que he estudiado con algo más detenimiento en otro lugar (Boix Palop, 2015a) si no hubiera habido una reacción coordinada de actores sociales, locales y autonómicos, finalmente avalada por el Tribunal Constitucional, para preservar ciertos espacios competenciales conscientemente amenazados por la misma.

Una nueva ley local que mirara con ambición al futuro habría de proceder a una cuidadosa identificación de los problemas y fortalezas a partir de los que los actores públicos han de actuar en entornos urbanos y de las políticas públicas que por esta razón habrían de desplazarse a la escala local. Recordemos que las administraciones locales suelen ser tanto más eficaces para afrontar estos problemas por tener mucho más presentes y ser mucho más sensibles a las necesidades sociales de sus vecinos (Romero, 2015). Adicionalmente, habría de facilitar la prestación flexible y diversa, según las orientaciones políticas expresadas por los ciudadanos de cada municipio, de estos servicios sociales, permitiendo las diversas posibilidades con cierta neutralidad, sea mayor o menos la ambición, sea pública o privada la preferencia en cuanto al modo de gestión. El juicio que merece la RSAL desde estos parámetros es también, como podrá ya intuirse a estas alturas, muy negativo. A su ya comentada falta de ambición en materia de financiación y competencial une una evidente vocación recortadora y privatizadora, aunque en ocasiones lo sea de forma indirecta y no explícita, que condiciona el ejercicio del poder por parte de mayorías que quieran hacer un despliegue socialmente ambicioso y con prestación pública. Es ésta, de hecho, una de sus características más nocivas de la ley, tanto más cuanto quizás se trate de una de las que más inadvertida haya pasado para los juristas. Resulta muy significativo que el modelo de prestación incentivado por la reforma, que favorece la externalización, esté poniendo en muchas dificultades a algunas de estas nuevas corporaciones municipales surgidas de las elecciones de 2015 -en gran parte como respuesta, justamente, a la percepción ciudadana de que era preciso modificar el rumbo de las políticas públicas desarrolladas hasta esa fecha- para poner en práctica sus nuevas políticas en aplicación del mandato democrático. No sólo no es sencillo, en ocasiones también por efecto del Derecho europeo (Gimeno Feliú, 2016), remunicipalizar servicios municipales, como se ha explicado por ejemplo en esta revista no hace mucho (CastiIlo Blanco, 2016; Tornos Mas, 2016). Tampoco es fácil con la ley de 2013 prestar directamente, desde el propio sector público, aquellos nuevos servicios a los ciudadanos que se desean implantar. En ocasiones es por falta de financiación -problema ya comentado-, en otras por la estructura rígida de personal impuesta por las normas en materia de contención del déficit -con reglas absurdas y manifiestamente contrarias a la autonomía que, teniendo dinero, impiden 
la contratación de empleados públicos y obligan a contratar la prestación con actores externos al sector público-, y en otras directamente porque es mucho más sencillo jurídicamente poner en marcha una prestación externalizada a partir de las nueva reglas en materia de gestión indirecta de servicios de la reforma local de 2013, que multiplica cautelas e informes de sostenibilidad cuando se ponen en marcha prestaciones realizadas desde la Administración y libera de casi todos estos controles cuando se externalizan (Villar Rojas, 2016). Permitir un modelo más atento a las diversas posibilidades de gestión, a todas, y así amparar las decisiones democráticas de la ciudadanía en este sentido, máxime cuando ello es consecuencia de una situación social que se quiere paliar mandatando a los representantes para poder poner en práctica políticas sociales más ambiciosas, debiera ser también una prioridad de cualquier reforma legal futura de nuestro gobierno local.

\section{BIBLIOGRAFÍA}

Se adjuntan las referencias a los trabajos mencionados en el texto. Todos ellos son textos de referencia sobre la realidad y reforma recientes del régimen local español (o de reformas extranjeras relevantes) de gran contenido informativo, que resultan muy aconsejables, en su totalidad, para la profundización en los aspectos tratados. Adicionalmente, el autor de este trabajo, junto a la prof. Ana María de la Encarnación Valcárcel, es editor de una obra colectiva dedicada al análisis exhaustivo de muchos de los fenómenos descritos en el mismo: A. BOIX PALOP y A. M. DE LA ENCARNACIÓN VALCÁRCEL, Los retos del gobierno local tras la reforma de 2013, Aranzadi, 2015.

ALMEIDA CERREDA, M. (2013), "La reforma de la planta, estructura competencial, organización y articulación de la Administración local”, en La planta del Gobierno local, AEPDA, págs. 61-122.

ALONSO MAS, M. J. (2014), "Normas básicas sobre régimen local, estatutos de autonomía y normas autonómicas de desarrollo", en DOMINGO ZABALLOS, M. J. (coord.), Reforma del Régimen Local: la Ley de Racionalización y Sostenibilidad de la Administración Local: veintitrés estudios, Aranzadi.

ARENILLA SÁEZ, M. (2014), "El nuevo sistema de competencias locales”, en SANTAMARÍA PASTOR, J. A. (coord.), La reforma de 2013 del régimen local español, Fundación Democracia y Gobierno local, págs. 15-55.

BAZOCHE, M. (2008), Département ou région? Les réformes territoriales de Fénelon à Jacques Attali, L'Harmattan. BEL, G. (2013), Anatomía de un desencuentro, Destino.

BOIX PALOP, A. (2013), Una nova planta per als valencians. Possibilitats i límits per a l’organització política i administrativa del País Valencià dins la Constitució de 1978, Nexe.

- (2014), "Sentido y orientación de la Ley 27/2013 de racionalización y sostenibilidad de la Administración local: autonomía local, recentralización y provisión de servicios públicos locales”, Revista de Estudios de la Administración Local y Autonómica, núm. 2.

- (2015a), "Apuntes sobre algunas consecuencias sociales de la reforma local de 2013", Papeles de relaciones ecosociales y cambio global, núm. 129, págs. 37-51.

- Andrés (2015b), "Reforma local de 2013 y sus consecuencias sobre la prestación de servicios públicos", en ROMERO, J. y BOIX, A. (coord.), Democracia desde abajo. Nueva agenda para el Gobierno local, PUV, págs. 61-78.

CARBONELL PORRAS, E. (2013), “La planta local: análisis general y perspectivas de reforma”, en La planta del Gobierno local, AEPDA, págs. 17-59.

CASTILLO BLANCO, F. (2016), "Remunicipalización de servicios locales y situación del personal de los servicios rescatados", en El Cronista Social y Democrático de Derecho, núm. 58-59, págs. 72-95.

DURÁN GARCÍA, EL CRONISTA, F. J. (2016), "La fusión coactiva de municipios en España: principios, estrategia y resultados”, El Cronista del Estado Social y Democrático de Derecho, núm. 57, 2016, págs. 44-51.

FORCADELL I ESTELLER, X. (2014), “Aproximación crítica a los principales cambios en la legislación de régimen local como consecuencia de la aprobación de la Ley 27/2013, de 27 de diciembre, de racionalización y sostenibilidad de la Administración Local”, en SANTAMARÍA PASTOR, J. A. (coord.), La reforma de 2013 del régimen local español, Fundación Democracia y Gobierno local, págs. 57-73.

GARCÍA RUBIO, F. (2011), "El régimen especial de los municipios de gran población”, en MUÑOZ MACHADO, S. (Dir.), Tratado de Derecho Municipal, tomo IV, tercera edición, lustel, págs. 4.327-4.378.

GIMENO FELIÚ, J. M. (2016), “Remunicipalización de servicios locales y Derecho comunitario”, en El Cronista Social y Democrático de Derecho, núm. 58-59, págs. 50-71.

HERTZOG, R. (2012), "Local government in France”, en MORENO, A. M. (coord.), Local government in the Member States of the European Union: a comparative perspective, INAP, págs. 203-231.

LAGO PEÑAS, S. y MARTÍNEZ VÁZQUEZ, J. (2013), The Challenges of Local Government Size, Edward Elgar.

- (2014), “La política tributaria y las corporaciones locales: elementos de análisis y discusión”, Papeles de economía española, núm. 139, págs. 115-124.

MEDINA ALCOZ, L. (2016), "La distribución de competencias entre el Estado y las Comunidades Autónomas a la luz de las Sentencias constitucionales sobre la reforma local de 2013”, Anuario del gobierno local (en prensa). 
MORCILLO MORENO, J. (2014), “La racionalización de los entes locales en Italia: a la sombra de la incertidumbre”, Revista de Administración Pública, núm. 195, págs. 303-336.

MORENO, A. M. (2012), Local government in the Member States of the European Union: a comparative perspective, INAP.

NAVARRO RODRÍGUEZ, P. y ZAFRA VÍCTOR, M. (2014), “El pretendido blindaje autonómico de competencias municipales tras la reforma de la Administración Local”, Revista de Estudios de la Administración Local y Autonómica, núm. 2.

RODRÍGUEZ-ARANA MUÑOZ, X. (2002-2003), "Sobre la segunda descentralización”, Revista de Estudios Autonómicos, núm. 2-3, págs. 97-115.

ROMERO, J. y BOIX, A. (2015), Democracia desde abajo. Nueva agenda para el Gobierno local, PUV.

SANTAMARÍA PASTOR, J. A. (2014), "El régimen de competencias locales y el dilema de la esfinge", en SANTAMARÍA PASTOR, J. A. (coord.), La reforma de 2013 del régimen local español, Fundación Democracia y Gobierno local, págs. 139-156.

SCHEFOLD, D., “Local government in Germany”, en MORENO, A. M. (coord.), Local government in the Member States of the European Union: a comparative perspective, INAP, págs. 233-256.

TORNOS MAS, J. (2016), “La remunicipalización de los servicios públicos locales. Algunas precisiones conceptuales”, en El Cronista Social y Democrático de Derecho, núm. 58-59 págs. 32-49.

UCEDA, X. y MARTÍNEZ, L. (2015), "Servicios sociales en la Comunidad valenciana”, en ROMERO, J. y BOIX, A. (coord.), Democracia desde abajo. Nueva agenda para el Gobierno local, PUV, págs. 207-233.

VELASCO CABALLERO, F. (2010), (Dir.) Gobiernos locales en Estados federales y descentralizados: Alemania, Italia y Reino Unido, Institut d'estudis Autonòmics.

- (2014), "Títulos competenciales y garantía constitucional de la autonomía local en la Ley de Racionalización y Sostenibilidad de la Administración Local”, en SANTAMARÍA PASTOR, J. A. (Coord.), La reforma de 2013 del régimen local español, Fundación Democracia y Gobierno Local, págs. 75-136.

- (2015), "Desarrollos autonómicos de la Ley de Racionalización y Sostenibilidad de la Administración Local”, Anuario de Derecho Municipal 2014, Marcial Pons-UAM, págs. 21-53.

VILLAR ROJAS, F. J. (2016), “Implicaciones de los principios de sostenibilidad y estabilidad presupuestaria en los modos de gestión de los servicios públicos locales”, en El Cronista Social y Democrático de Derecho, núm. 5859 págs. 96-106. 